of Physiology at Toronto from 1929 until his retirement in 1965. He directed the Best Institute, and the Banting and Best Department of Medical Research, following the death of Banting in 1942 . He maintained his interest in insulin and carbohydrate metabolism throughout his career. $\mathrm{He}$ also published research on histamine and heparin, and on choline and fatty livers. He was a Canadian, born in Maine, and was much sought as a lecturer on both sides of the Atlantic. He was a man of true humility, dignified, yet buoyant and outgoing; reserved, yet friendly and informal with all who met him. He was filled with a youthful enthusiasm and was always devoted to research. $\mathrm{He}$ married Margaret Mahon in 1924 and they had two sons, one of whom, Charles Alexander, predeceased his father by a few days.

A climber once said: 'I have no doubt that others will follow our track to the summit . . . but never again will any one feel the inspiration, the excitement and the glory of success that we three experienced when the first ascent was made.' Such a moment must have come to Banting and Best in July 30, 1921, when the color reaction showed a steady drop in a dog's blood glucose during the hours following the first injection of insulin.

Thomas H. Jukes

\section{G. J. Hoytink}

Physical chemists everywhere have been saddened to learn of the sudden death, on 11 April 1978, of Gerrit Jan Hoytink, Professor of Physical Chemistry in the University of Sheffield.

Jan Hoytink was born in Alkmaar, North Holland, on 14 January, 1925. $\mathrm{He}$ studied at the Free University in Amsterdam and after presenting his Ph.D. thesis in 1952 was appointed Lecturer in Physical Chemistry in 1953. In 1957 he became the first Professor of Physical Chemistry at the Free University and in 1960 moved to the Chair of Physical Chemistry at the University of Amsterdam. He remained there for six years before moving to Sheffield.

The theme of all his work was to account for the properties of conjugated molecules, usually aromatic hydrocarbons, using molecular orbital theory. This began immediately with his Ph.D. research, in which he investigated resonance energies by interpreting heats of combustion and the energies of the lowest singlet-singlet transition for several types of conjugated system. His first independent work, which was to quickly establish his reputation, was to measure the reduction potentials of aromatic hydro- carbons and interpret them using semiempirical molecular orbital theory. It was at about this time that it was first reported that the coloured compounds formed on exposure of hydrocarbon solutions to alkali metals were paramagnetic and he quickly realised that the species formed in the two types of reaction were identical.

$\mathrm{He}$ went on to appreciate the significance of the pairing theorem for spectroscopic properties of radicalanions and cations, to interpret the optical spectra of radical-anions using molecular orbital theory with configuration interaction, and to illustrate how configuration interaction gave a good account of the appearance of negative spin populations in certain radicals and radical-ions. $\mathrm{He}$ thus played a seminal role in opening up the field of radical ions, systems which for the last ten years have rated their own biennial Gordon Conference. He became interested in triplet states, in particular ground-state triplets expected for the dinegative ions of hydrocarbons of high symmetry, in radiationless transitions, and in radiative transitions of mononegative ions. Latterly he used nano-second and ultimately pico-second laser flash photolysis to probe still further the excited states of hydrocarbon anions.

$\mathrm{He}$ had a high-minded view of his own work: he liked things to be done properly and would not spend time on things he regarded as trivial just to create an effect. Similarly with the teaching of physical chemistry, he was most unhappy with any suggestion that one might try to (over) simplify things in order to give the students an easier ride. This commitment to intellectual rigour has left its mark in at least two ways. First, in the high standards of assessment which he set as an early Chairman of the Dutch Chemical Foundation, and which prevail to this day. Second, in the standard he set for Chemical Physics Letters, the journal which he encouraged North-Holland to publish, and whose editor he was from its foundation in 1967. In this he had little sympathy for offerings where he detected a hint of entrepreneurism but was disposed to look with a kindly eye on anything he regarded as an honest effort, particularly, perhaps, if the authors were felt to be in a situation where it was difficult to do any research at all. He used to say that he thought the important thing was that a paper would be stimulating. This was presumably not the whole of his editorial philosophy, but in any event he delivered, nursed, and developed a most successful and highly regarded journal.

Jan Hoytink did not always live easily with the world or with himself, and his life was turbulent. On the one hand he needed to be true to himself and tell things as he saw them, on the other, his nature was not such as to insulate him from the natural shocks that flesh is heir to. Through all, he was a good man, who illumined science and life for his many friends.

N. M. Atherton

\section{A. D. Thackeray}

Andrew David Thackeray, former Director of the Radcliffe Observatory Pretoria and one of the most distinguished British astrophysicists, was killed in an accident on 21 February, 1978.

David Thackeray was born in 1910 and was educated at Eton and Kings College Cambridge. His early research work at Cambridge and at the Mount Wilson Observatory California was on various topics in solar and stellar spectroscopy. He made an early and outstanding contribution to astrophysics by resolving a long-standing problem relating to Mira-type variables. Some emission lines found in the spectra of these stars show quite unusual relative intensities. It occurred to him that this was the effect of resonance excitation and he worked out a detailed explanation which still holds. $\mathrm{He}$ joined the staff of the Solar Physics Observatory Cambridge in 1937. The end of World War II found him serving with a Quaker Unit in Italy.

In 1948 he went to South Africa as Chief Assistant at the Radcliffe Observatory Pretoria. The $1.9 \mathrm{~m}$ reflector, then the largest in the Southern Hemisphere, was just coming into action and he was to devote the rest of his life to the full exploitation of this telescope. $\mathrm{He}$ succeeded Dr H. Knox-Shaw as Director in 1950 and remained in that post till the Pretoria site was closed in 1974. The $1.9 \mathrm{~m}$ reflector was acquired at that stage by the South African Astronomical Observatory for its main Observatory at Sutherland Cape Province and David Thackeray became Radcliffe Professor of Astronomy at the University of Cape Town where he remained active in astronomical research till his death. His many publications cover almost all aspects of astronomy and only a few can be mentioned.

He discovered (with A. J. Wesselink) that the Magellanic Clouds (the two nearest galaxies) were twice as distant as previously thought. He announced this at a Rome meeting in 1952. At this meeting the American astronomer, Baade, announced a similar result for the Andromeda Galaxy but on less certain grounds. These results doubled the accepted age of the Universe and 
resolved the paradox that the current age was smaller than the age of the Earth. His work on the Magellanic Clouds also showed that they were a mixture of both old and young stars contrary to earlier suppositions. In contrast his work on the Sculptor Galaxy was largely responsible for establishing that such spheroidal galaxies consisted entirely of old stars. With his collaborators he made extensive spectroscopic studies of stars in the Magellanic Clouds. This established an upper limit to stellar brightness at about a million times the solar luminosity. Stars at this limit showed evidence of instability. Again with his collaborators, extensive radial velocity measurements were made in Pretoria of stars in the Southern Milky Way. This led to new determinations of the constants of galactic rotation and an estimate of the distance to the galactic centre.

Although active in many fields David Thackeray regarded himself primarily as a stellar spectroscopist and his knowledge of this field was encyclopaedic. He was particularly interested in objects with unusual spectra and the significance of this work is only slowly being realised. Thus his investigations over many years of the eclipsing symbiotic star AR Pav is a major clue to the understanding of symbiotic stars. His main legacy in this field is his studies extending over nearly 30 years of the enigmatic exploding object Eta Carinae and the slow nova RR Telescopii. In these objects he identified forbidden emission lines not yet produced in the laboratory and his detailed studies must form the basis of any theory of these puzzling objects. His discovery of strong polarisation in the halo around Eta Carinae is of particular importance.

David Thackeray approached observations with an open mind and complete integrity; refusing to draw any conclusions which were not completely justified. He was remarkably observant and rarely failed to notice an interesting feature in a spectrum even on a brief examination (often in the darkroom when the plate was still washing). In 1949 he noted visually with the $1.9 \mathrm{~m}$ telescope variation in brightness of VV Pup on a time scale of seconds. This seemed hardly credible at the time but 20 years later the result was fully confirmed using high speed photometers and is an important property of cataclysmic variables.

David was an enthusiastic observer of all natural phenomena and published a number of notes on them. The last of these on 'Dust-Devils and Spray-Devils' was published in October 1977. It was, in fact, a violent dust devil that overturned the vehicle in which he was a passenger on February 21. He had completed a successful week's observing with the $1.9 \mathrm{~m}$ telescope at Sutherland and was returning to Cape Town. He was killed instantly.

He more than any other single person opened up the Southern Hemisphere to modern astrophysics. His work was done quietly and without publicity but it has established his name at the very front of international astronomy.

Astronomers throughout the world will remember David's kindness, courtesy and humour. Many were privileged to enjoy the hospitality of David and Mary and their children in a home where astronomy blended naturally with music. He particularly welcomed and helped the many young British astronomers who came to work in Pretoria and in this way he made an important contribution to the development of astronomy in the United Kingdom.

Long a Fellow of the Royal Astronomical Society (London) he was elected an Associate a few days before his death; the first British subject to be accorded this honour. The news was waiting his return to Cape Town.

M. W. Feast

\section{Victor Eyles}

DR VICTOR EYLES, F.R.S.E., who died on 8 March 1978 at the age of 82 was the leading British historian of geology and one of the world's most eminent workers in this field.

He was a native of Bristol and after service during the first world war, first with the Royal Engineers and later as Observer with the Kite Balloons of the Royal Flying Corps, he graduated in 1920 in petrology at Bristol University. He had a long and distinguished career with the Geological Survey of Great Britain (1920-1955). In the years before the war he worked in Scotland and Northumberland making notable contributions to our knowledge of the Carboniferous sedimentary and igneous rocks of Ayrshire and Renfrewshire and the ancient crystalline (Moine) schists of the West Highlands.

In 1940 he was selected to report to the Non Ferrous Ores Committee of the Ministry of Supply on the bauxite deposits associated with Tertiary lavas of Antrim, Northern Ireland, and was later commissioned by the Ministry of Aircraft Production to carry out an extensive programme of exploration by boring. This proved 750,000 tons of bauxite, which, though rich in iron, was of commercial grade. By 1944 about 250,000 tons of the bauxite had been mined, and this produced 35,000 tons of aluminium for British aircraft, freeing valuable shipping space for the import of other essential raw materials. After the war Eyles was based in the London Office of the Geological Survey, in charge of the field units working in the Midland and South Wales Coalfields.

Dr Eyles' eminence as a historian of geology springs from a number of deeply researched bio-bibliographical articles on pioneer geologists and their work. Outstanding examples are the paper on Hutton's original statement of the Theory of the Earth and his detailed account of the Swiss geologist, L. A. Necker. Eyles was instrumental in securing the eventual publication of Necker's map of Scotland, which had been completed in manuscript in 1808 . Other early geologists whose work has been described by Eyles are J. MacCulloch, Robert Jameson, Sir James Hall and A. G. Werner. Together with his wife, Joan, he wrote a most valuable account of William Smith's great geological map of England and Wales. He also contributed some excellent general articles on the history of science, such as his account of the history of scientific activity in the Bristol region, presented at the British Association's Bristol meeting in 1955. More recently he outlined suggestions for further research in the history of geology in an article published in History of Science in 1966, and a summary of his detailed knowledge of the state of eighteenth century geology was set forth in the New Hampshire Symposium published in 1969.

Eyles' interest in the history of his science was greatly stimulated by the fine collection of early geological maps and texts which he and his wife built up over the years. Between 1951 and 1956 he gave courses on the history of geology at University College London, and he lectured at several universities in the USA. He was the United Kingdom representative on the International Committee on the History of Geological Sciences from 1967 to 1972 and was an honorary member of the Society for the Bibliography of Natural History.

Victor Eyles was a man of very few words, every one of which was well chosen. He was one of the most courteous and considerate of men with a wonderfully dry sense of humour, and was prepared to spend almost endless time in providing guidance to others in his chosen field of study. He was definitely a geologist turned historian of geology and his knowledge of both these aspects has made him the doyen of historians of geology in the British Isles.

N. E. Butcher W. Mykura 